\title{
Análise de padrões de coordenação interpessoal no um-contra-um no Futebol
}

\author{
Pedro Passos \\ Ricardo Lopes \\ João Milho
}

https://doi.org/10.5628/rpcd.08.03.365

\section{RESUMO}

O futebol apresenta constrangimentos de tarefa específicos que o diferenciam de outros desportos de equipa como o basquetebol e/ou o rugby. Para perceber como é que estes constrangimentos específicos influenciam a coordenação interpessoal, procedeu-se à análise de uma sub-fase do jogo de futebol, o um-contra-um. O suporte teórico assentou na Abordagem Dinâmica, a qual justifica como o comportamento dos jogadores se altera e evolui sob constrangimentos da acção. O movimento dos jogadores foi captado por uma câmara de vídeo digital. As imagens foram digitalizadas com o software TACTO 7.0. Na reconstrução do espaço bidimensional foi utilizado o método das Transformações Lineares Directas (DLT), para o qual foi desenvolvido um software específico focado na utilização amigável na perspectiva do utilizador. Com base nos resultados, concluiu-se que um-contra-um forma um sistema dinâmico auto-organizado, no qual o comportamento do defesa e do atacante não é conduzido por informação exterior ao sistema diádico, mas por informação presente no contexto. O software de reconstrução bidimensional demonstrou ser consistente para uma análise fenomenológica de situações de um-contra-um no futebol, o que sugere que a sua aplicação seja extensível a outros cenários desportivos, para análise da coordenação interpessoal em tarefas desportivas.

Palavras-chave: coordenação interpessoal; transições de fase; reconstrução espaço bidimensional
Universidade Lusófona de Humanidades e Tecnologias

\section{ABSTRACT \\ Analysis of the interpersonal coordination patterns in football one-on-one Play}

Soccer presents task constraints different from other team sports such as basketball or rugby. In order to analyse how that specific task constraints conditioning the interpersonal coordination patterns we proceed to analyse a sub-phase of the soccer game, the one versus one. The theoretical background was supported by the Dynamical Approach to describe how players' behaviour alter and evolve under specific action constraints. Players' motion was recorded by a single digital video camera. The images were digitized with the software TACTO 7.0. For the reconstruction of the bidimensional space the Direct Linear

Transformations method was used. Sustain on this method we had developed our own software with the main focus to be user friendly. Based on the data we can conclude that one versus one behave as a selforganize dynamical system, and players behaviour it is not exclusively drive by internal information but by information available in the performance context. Moreover our software shows to be an accurate tool for a bidimensional reconstruction allowing a phenomenological analysis of $1 v s 1$ situations in soccer. We suggest an extended application to other team sports.

Key-words: interpersonal coordination, phase transitions, bidimensional reconstruction 


\section{INTRODUÇÃO}

Análise do desempenho desportivo em desportos de equipa, tem sido uma das principais preocupações das ciências do desporto nas últimas décadas. Identificar as razões pelas quais algumas equipas alcançam sucesso, é um objectivo comum da literatura em ciências do desporto. As metodologias usadas para estudar o desempenho desportivo, têm sido muitas vezes aplicadas para procurar diferenças nas decisões e acções de equipas e atletas de sucesso com os menos bem sucedidos(20). Neste âmbito, os sistemas notacionais tem sido um instrumento amplamente utilizado. Contudo e apesar da importância dos dados recolhidos a partir dos sistemas notacionais, duas críticas podem ser feitas: i) a ausência de suporte teórico, no que respeita à escolha das variáveis a serem analisadas e; ii) a análise de desempenho é baseada em variáveis discretas e descontínuas. Esta última crítica, leva a que os dados usualmente nos informem em relação "ao que acontece" e não em relação ao "como" e "porque é que acontece"? Esta característica, faz com que os sistemas notacionais sejam um registo isolado de acções que ocorrem durante um jogo, e não um processo exploratório de pesquisa, de quais as razões que levam uma equipa a decidir e desempenhar um conjunto de acções que a conduzem ao sucesso. Para além disso, a variabilidade de comportamentos que jogadores e equipas demonstram, quando jogam contra diferentes adversários em diferentes jogos, realça a incapacidade dos sistemas notacionais em identificar o que McGarry e colegas chamam "assinaturas de desempenho" (i.e. traços comuns de comportamento que se manifestam ao longo de vários jogos) com base apenas em gestos técnico-tácti$\cos ^{(13)}$. Os mesmos autores, sugerem que para uma válida descrição do comportamento de uma equipa enquanto sistema, há que identificar padrões de coordenação espaço-temporais inter e intra-equipa, que caracterizem os desportos de equipa como sistemas dinâmicos auto-organizados.

A observação de sub-fases do jogo, como as situações de um-contra-um, observáveis em qualquer desporto de equipa com bola como o basquetebol, o rugby ou o futebol, permitem a análise de comportamentos das díades atacante-defesa com o objectivo de caracterizar padrões de coordenação interpessoal.
Nesta linha de investigação, Ribeiro e Araújo(17) referem que é da multiplicidade das acções individuais (i.e. do atacante e do defesa), que emergem os comportamentos colectivos (i.e. comportamento da díade atacante-defesa), que visam criar situações propícias para alcançar os objectivos da equipa. Com a finalidade de descrever, como é que os constrangimentos específicos do futebol, influenciam a tomada de decisão e a coordenação interpessoal, a presente investigação consistiu em analisar as díades atacante-defesa em situação de um-contra-um no futebol, tendo como suporte teórico a Abordagem Dinâmica $(5,23)$. Esta abordagem envolve conceitos da Psicologia Ecológica e da Teoria dos Sistemas Dinâmicos. Os processos cognitivos como a tomada de decisão, têm sido estudados no desporto, assumindo que a decisão e a acção são mediadas por representações mentais da realidade, armazenadas em memórias, que posteriormente, são implementadas pelas estruturas executivas ${ }^{(1,5)}$. Porém, esta perspectiva cognitivista confronta-se com o problema do espaço na memória para armazenar toda a informação de cada situação já experienciada, bem como o problema do tempo durante uma acção desportiva para detectar, identificar, associar, comparar, seleccionar, programar e executar uma resposta. Para além disso, a perspectiva cognitivista apresenta algumas dificuldades em explicar a criatividade e a adaptabilidade humana, exigidas pela dinâmica e variabilidade dos jogos desportivos de equipa(16).

Sustentada nos problemas identificados na perspectiva cognitivista (i.e. espaço de armazenamento na memória; e tempo para o processamento de informação) no que respeita à tomada de decisão e acção(4), a abordagem ecológica tem demonstrado como a informação disponível no contexto e não apenas a que está armazenada na memória, constrange as acções do praticante durante o treino ou a competição. Utilizando como exemplo o futebol, o treino das aç̧ões tácticas desenrola-se de acordo com um plano determinado de organização, estabelecendo antecipadamente os princípios de circulação dos jogadores e da bola, bem como o sentido, o ritmo de jogo, etc. No entanto, estes movimentos pré-determinados, repetidos e supostamente memorizados nos treinos, a maior parte das vezes não são aplicados na competição, pois o envolvimento, as acções dos jogadores 
da equipa adversária e o posicionamento dos próprios jogadores em função dos adversários não o permitem, ou seja, estão descontextualizados. Segundo Araújo(5) as situações desportivas não são previamente resolvidas na "cabeça" do praticante, nem são exclusivamente resolvidas por este. $\mathrm{O}$ atleta, mesmo com planos prévios de acção, explora e alcança aquilo que o contexto permite. No caso do futebol, um jogador executa um remate quando o contexto o permite, ou seja, é necessário estar sem oposição (i.e. sem um defesa à sua frente), a uma distância da baliza que lhe permita executar o remate com força e colocação suficiente, para que tenha sucesso. No caso de num determinado momento, haver oposição por parte de um defesa, o contexto (i.e. o defesa) não permite ao atacante realizar o remate com sucesso, mas poderá por exemplo, permitir-lhe efectuar o passe para um companheiro livre de marcação ou de oposição directa. Segundo o mesmo autor, os contextos desportivos são caracterizados pela variabilidade e implicam que o atleta seja activo, que acompanhe a dinâmica do que se passa à sua volta, em vez de passivamente esperar estímulos e dar respostas. Para percepcionar, o atleta tem de procurar através da acção a informação que está disponível no contexto, a qual está em constante modificação(9). Tal como noutros desportos de equipa, no futebol, considerando a dinâmica e a variabilidade do contexto, não fará sentido analisar a tomada de decisão com base em comportamentos pré-estabelecidos, pois as decisões dos jogadores encontram-se condicionadas por aquilo que o contexto permite fazer. Neste sentido, para estudar a tomada de decisão no desporto é fundamental atender-se à estrutura do contexto, ao objectivo da tarefa e à dinâmica da interacção indivíduo-ambiente. Tendo como suporte teórico a abordagem dinâmica, e mais concretamente os fundamentos da Psicologia Ecológica, podemos considerar a especificidade do contexto de cada modalidade e a sua influência na tomada de decisão, a qual não deve ser abordada como algo determinado à partida, mas como resultado da interacção do sujeito no contexto em que se encontra inserido(5).

Por outro lado, a Teoria dos Sistemas Dinâmicos permite compreender o modo como os sistemas complexos não-lineares (p. ex. sub-fases de jogo como o um contra um), mudam ao longo do tempo.
Referimo-nos aqui a mudanças na estrutura organizacional do sistema (p.ex. quando numa díade atacante-defesa no futebol, o atacante deixa de ser o jogador mais afastado da baliza), sendo estas modificações justificadas à luz da abordagem dinâmica como sendo processos auto-organizados. Segundo Araújo(5) auto-organização "deve ser entendida como uma reorganização súbita dos elementos de um sistema sob certas condições. A auto-organização é manifestada como uma transição entre diferentes estados organizacionais" (i.e. estados de ordem). Um sistema complexo autoorganizado, não necessita de qualquer ordem exterior para manter ou alterar o seu estado de ordem. Por exemplo, numa situação de 1v1 no futebol, o atacante procura ultrapassar o defesa, enquanto este procurar evitar que o atacante seja bem sucedido, ao contrariar as decisões e acções do atacante, o defesa coloca constrangimentos de tarefa que conduzem a díade atacante-defesa para uma acção não consciente de coordenação interpessoal, os estados de ordem desta díade e as suas transições, podem caracterizarse em função da estrutura organizacional do sistema, ou seja, qual o jogador que se encontra mais próximo da baliza em cada momento no tempo. Aqui coloca-se o problema de como emergem os padrões de coordenação interpessoal. Para efeitos de coordenação intra-pessoal, Bernstein( ${ }^{(6)}$ propõe que a coordenação de movimentos emerge da interacção dos constrangimentos, os quais organizam os graus de liberdade do corpo humano durante o processo de aprendizagem. Num desporto de equipa com bola, como o futebol, existe uma diversidade de graus de liberdade (p.ex. trajectórias de corrida dos jogadores; quantidade de ligações possíveis que se podem estabelecer entre jogadores da mesma equipa), daí que para existir coordenação esses graus de liberdade tenham que ser constrangidos, isto é, limitados por uma ligação. Tal como sucede para investigações realizadas em desportos de equipa com bola como o basquetebol(17) ou o rugby(15), sugerimos que também no futebol, os jogadores estão ligados entre si através de acoplamentos de percepção-acção constrangidos por objectivos, posições no campo e princípios do jogo. A emergência de padrões de coordenação interpessoal, só está disponível quando os jogadores se ligam entre si através de acoplamentos de percepção-acção. Os princípios de jogo aju- 
dam a formar as estratégias de jogo, são um conjunto de informações e objectivos partilhados pelos onze jogadores de uma equipa, que os mantém ligados num comportamento colectivo direccionado para o objectivo. Por exemplo, o princípio da contenção, princípio específico da defesa, faz com que uma equipa quando perde a posse da bola, coordene as decisões e acções com finalidade de a recuperar ${ }^{(7)}$. Ou seja, os acoplamentos de percepção-acção ligam os jogadores entre si, conduzindo à emergência de padrões de coordenação interpessoal, que se manifestam em comportamentos colectivos, possibilitando a recuperação da posse de bola.

Para descrever como emergem os padrões de coordenação interpessoal nos desportos colectivos com bola, sugerimos como suporte teórico o Modelo de Constrangimentos de Karl Newell(14). Este modelo descreve que o comportamento motor é emergente (i.e. sem qualquer ordem exterior) devido à interacção mútua e recíproca entre três categorias de constrangimentos: i) do indivíduo, ii) do envolvimento e iii) da tarefa.

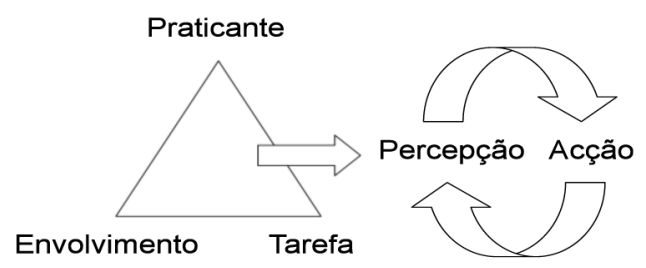

Figura 1. Modelo dos constrangimentos de Newell.

Os constrangimentos do indivíduo referem-se às características dos atletas, sejam elas físicas (p.ex. peso, altura), morfológicas (p.ex. força máxima, velocidade, resistência), psicológicas (p.ex. ansiedade, auto-confiança, motivação, liderança, atençãoconcentração), técnicas (p.ex. capacidade de passe, de remate, etc.) ou tácticas (p.ex. "leitura de jogo"). Os constrangimentos do envolvimento podem ser físicos (p.ex. estado do campo, luminosidade), sociais (p.ex. público hostil, presença de familiares e amigos). Os constrangimentos da tarefa incluem os objectivos para cada sub-fase do jogo, as regras, os materiais, os equipamentos, os campos e as suas marcações, o número de praticantes, etc. Segundo Araújo(5), estes constrangimentos não retiram a liberdade ao sistema, antes pelo contrário, justificam a forma como os componentes do sistema se encontram ligados entre si, formando um tipo específico de organização, possibilitando que dentro do espaço de jogo todas as soluções sejam possíveis.

Numa perspectiva aplicada ao treino, a manipulação dos constrangimentos passa por exemplo, por aumentar ou diminuir o tamanho do campo, jogar ou não em superioridade numérica, alterar as regras porém sem descontextualizar a modalidade, dito por outras palavras, que sejam situações simuladas de competição. Por exemplo, num treino de futebol, introduzirmos uma regra que condicione os jogadores a utilizarem apenas dois toques (i.e. passe e recepção), esta regra irá provocar que a velocidade de execução das acções técnico-tácticas aumente, diminuído o tempo que os jogadores têm para decidir e agir, aumentando a exigência na tomada de decisão.

Para além disso, Seeley ${ }^{(19)}$, defende que nos desportos de equipa com bola, como é o caso do futebol, pode ser concebido um tipo específico de constrangimentos referentes à equipa. Segundo o mesmo autor, e à semelhança dos constrangimentos do individuo, também os constrangimentos da equipa se centram na interacção equipa-envolvimento para manter um comportamento colectivo direccionado para o objectivo. Cada jogador tem uma função específica, que está coordenada com a função do seu colega mais próximo, levando à obtenção de objectivos globais ao nível da equipa. Por exemplo, quando uma equipa não se encontra na posse de bola, o objectivo será recuperar a sua posse, para tal os jogadores na defesa vão coordenar as suas acções para atingirem esse objectivo. Assim, quando um jogador faz contenção (princípio específico da defesa), o seu colega mais próximo fará cobertura defensiva (princípio específico da defesa) apoiando o colega que faz contenção, para que de forma coordenada ajam colectivamente aumentando as possibilidades de recuperar a posse de bola(7). Tal como foi referido antes, a coordenação interpessoal sustentada em acoplamentos de percepção-acção, faz com que emirjam comportamentos diádicos (p.ex. atacante-atacante) direccionados a um objectivo, como seja, recuperar a posse de bola. Quando se efectua a recuperação 
da posse da bola, não é um único jogador que a recupera, mas sim toda a equipa, pelo que todos os jogadores deverão estar preparados para desempenhar qualquer tipo de função.

No contexto do jogo de futebol existem determinado tipo de informações, as quais são percepcionadas segundo as características de cada jogador. Este tipo de informações são caracterizadas como possibilidades de acção ou affordances(10), nas quais as capacidades de acção do praticante irão influenciá-lo no momento de percepcionar. Por exemplo, um atacante com bola face ao seu adversário directo, vai procurar explorar qual o caminho ideal para o ultrapassar, ou seja, quais as possibilidades de acção que o defesa lhe oferece em cada instante do jogo.

\section{Coordenação interpessoal no um contra um}

Apesar dos jogadores não possuírem um mecanismo neuronal comum, existe evidência experimental da existência de padrões de coordenação interpessoal em situações de um contra um no basquetebol(17) e no rugby ${ }^{(15)}$. Turvey(21) define coordenação como o processo pelo qual se ligam os componentes de um sistema, estabelecendo uma relação específica, durante uma actividade direccionada para um objectivo. Num contexto competitivo como os desportos de equipa com bola, os adversários cooperam em sinergias atacante-defesa, ao concordarem desempenhar nas condições formadas pelo ambiente e pelas regras do desporto(4).

Porém, há que referir que os padrões de coordenação interpessoal são específicos de cada modalidade devido à influência dos constrangimentos de tarefa, tais como, a forma da bola, o tamanho do campo, ou a posição relativa do adversário. No futebol, as fases do jogo são definidas através da posse ou não da bola. É esta que determina quem defende e quem ataca. Assim, quem ataca, encontrando-se na posse de bola tem como principal objectivo finalizar (i.e. marcar um golo), quem defende, não estando na posse de bola, tem como principal objectivo impedir a finalização. Deste modo, o defesa procura manter o equilíbrio, contrariando as acções do atacante mantendo-se entre a bola e a baliza, enquanto o atacante procura uma forma de atingir o seu objectivo, ultrapassando o defesa com a bola controlada e/ou finalizar, escolhendo uma via que rompa o equilíbrio exis- tente na díade atacante-defesa, dando-se uma mudança denominada na linguagem da Teoria dos Sistemas Dinâmicos como transição de fase. As situações de um-contra-um formadas pelas díades atacante-defesa são sub-fases de jogo, sendo característica destas díades o constante ajustamento no posicionamento dos jogadores, os quais se opõem para atingir os seus objectivos. Simplificando, os defesas procuram manter-se entre os atacantes e a baliza, de forma a impedirem a finalização e se possível recuperar a posse da bola, pelo contrário, os atacantes procuram destabilizar a oposição dos defesas para manter a posse de bola e quando possível finalizar. Podemos afirmar, que o sistema diádico atacante-defesa mantém o estado de ordem inicial quando o defesa se mantém entre a bola e a baliza, porém, se o atacante ultrapassa o defesa, dá-se uma transição de fase emergindo um novo estado de ordem $^{(4)}$. O facto de atacante e defesa formarem um sistema, implica o emergir de um novo reportório comportamental que só está acessível quando atacante e defesa se encontram ligados/acoplados entre si (e.g. o atacante não vai fazer uma finta se não estiver um defesa à sua frente), esta dinâmica comportamental irá atrair o sistema para determinados padrões de coordenação interpessoal(18).

Investigações realizadas no rugby, demonstraram que todos os movimentos do atacante para chegar à linha de ensaio são contrabalançados pelo defesa, o que indica que existe um tipo de coordenação interpessoal involuntária entre os jogadores ${ }^{(15)}$. O futebol, tal como o rugby, é um desporto colectivo de cooperação e competição. No entanto, diferenciamse pela superfície corporal utilizada para transportar a bola, nas características específicas do campo, nas regras do jogo, nas características da bola (e.g. peso, forma, textura). Por exemplo, um dos constrangimentos da tarefa que diferencia o futebol do basquetebol e do rugby é que a bola apenas pode ser conduzida com o pé, enquanto que no rugby e no basquetebol os jogadores podem utilizar as mãos. De acordo com o Modelo de Constrangimentos de Newell(14), diferentes constrangimentos de tarefa, implicam a emergência de diferentes padrões de coordenação motora.

Nas investigações realizadas na tomada de decisão e coordenação interpessoal no rugby ${ }^{(15)}$ e no basquete- 
bol(17) as transições de fase caracterizam-se por alterações na estrutura organizacional das díades atacante-defesa. Ao identificarem propriedades dos sistemas dinâmicos nas sub-fases de jogo um-contra-um, os estudos realizados sugerem que a díade atacantedefesa se comporta como sistema dinâmico autoorganizado que funciona a uma escala ecológica (i.e. em que a interacção entre componentes do sistema é sustentada por acoplamentos de percepção-acção), e no qual a informação que sustenta o comportamento deste sistema diádico, é gerada pelo próprio sistema (i.e. sugerindo-se por isso que é um sistema autoorganizado, não necessitando de qualquer ordem exterior para manter o comportamento).

Considerando que o um-contra-um no futebol também se comporta como um sistema dinâmico complexo, caracterizado por Júlio e Araújo(11) como sendo composto por diversos sub-sistemas que ao interagirem ao longo do tempo, produzem variados padrões de coordenação. Ao juntarmos a esta sugestão o facto do futebol apresentar constrangimentos de tarefa diferentes do rugby e do basquetebol, procuramos com esta investigação descrever como constrangimentos da tarefa diferentes do basquetebol e do rugby, poderão influenciar os padrões de coordenação interpessoal que emergem no comportamento das díades atacante-defesa no futebol.

Assim a presente investigação apresenta três objectivos: i) identificar transições de fase num desporto de equipa com constrangimentos diferentes do basquetebol e do rugby, para alcançar este objectivo recorremos a uma análise de sub-fases do jogo de futebol; ii) apresentar uma análise bidimensional das dinâmicas de coordenação interpessoal nas díades atacantedefesa no futebol; iii) demonstrar a aplicabilidade do método das Transformações Lineares Directas (Direct Linear Transformations, DLT) como instrumento de reconstrução do espaço bidimensional, com uma utilização amigável na perspectiva do utilizador.

\section{METODOLOGIA}

\section{Sujeitos}

Participaram neste estudo oito estudantes, do género masculino, do curso de Educação Física e Desporto da Universidade Lusófona de Humanidades e Tecnologias, com idades compreendidas entre os 22 e os 25 anos, os quais conhecem os princípios e regras do futebol. Os participantes interagiram em situações de um-contra-um, nas quais foi analisada a coordenação interpessoal entre atacante e defesa. Todos os participantes desempenharam a função quer de defesa, quer de atacante. A partir dos oito participantes criaram-se situações de um contra um com onze pares diferentes, o que dá um total de sessenta e quatro situações $(\mathrm{N}=64)$.

\section{Tarefa}

Foi utilizada uma sub-fase do jogo de futebol, o umcontra-um, num campo com a dimensão de cinco metros de largura por dez metros de comprimento. Como condição inicial, o defesa encontrava-se aproximadamente a meia distância e sobre a linha final, enquanto que $o$ atacante se situava aproximadamente a meia distância e sobre uma outra linha, no lado oposto do campo e paralela à linha final. As referidas linhas distavam dez metros uma da outra. O objectivo para o atacante consistia em passar a linha final com a bola controlada (linha que limita o campo e onde o defesa se posiciona antes de começar a sua acção), enquanto que o objectivo do defesa consistia em impedir o atacante de concretizar o seu objectivo. Há que referir que o comportamento de ambos os jogadores não estava pré-determinado, a partir do momento em que o atacante tocava com o pé na bola (sendo este o sinal definido para o início de cada situação). Porém, as acções quer do atacante quer do defesa estavam devidamente regulamentadas pelas leis do jogo de futebol. Foram filmadas sessenta e quatro $(\mathrm{N}=64)$ situações de um-contra-um, com o atacante situado a 10 metros do objectivo (Figura 2).

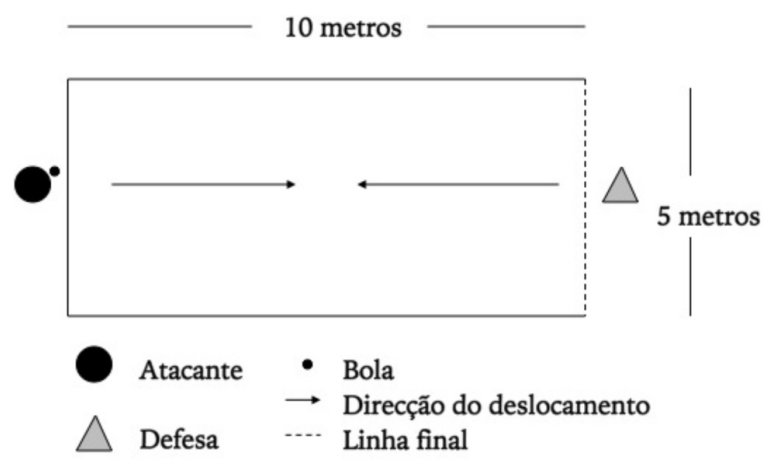

Figura 2. Esquema da tarefa. 


\section{Instrumentos}

O movimento dos jogadores foi gravado por uma câmara de vídeo digital marca Sony, modelo DCRTRV16E, colocada numa posição transversal em relação ao plano de deslocamento dos jogadores. Foram utilizados um tripé e uma cassete de vídeo. A bola utilizada respeitou as exigências impostas pela Federação Portuguesa de Futebol, de acordo leis de jogo de Futebol de onze(7), possuindo uma circunferência entre os $68 \mathrm{~cm}$ e os $70 \mathrm{~cm}$, um peso entre 410 g e 450 g e uma pressão entre os $600-1100 \mathrm{~g} / \mathrm{cm}^{2}$. Quatro coletes, dois verdes e dois laranjas, foram utilizados respectivamente, pelos defesas e pelos atacantes. Foram utilizados 36 sinalizadores (pinos), que serviram para marcar os pontos de referência para a reconstrução do espaço bidimensional.

\section{Procedimentos para Gravar a Acção de cada Jogador Posição da câmara-Justificação do plano}

Foi escolhido o plano transversal (ver Figura 3), pois permitia analisar com maior fiabilidade as dinâmicas de aproximação dos jogadores em oposição. A vantagem deste plano, é que durante a aproximação dos jogadores nunca corremos o risco de algum dos jogadores, em algum momento no tempo, encobrir o outro (situação que dificultaria o processo de digitalização).

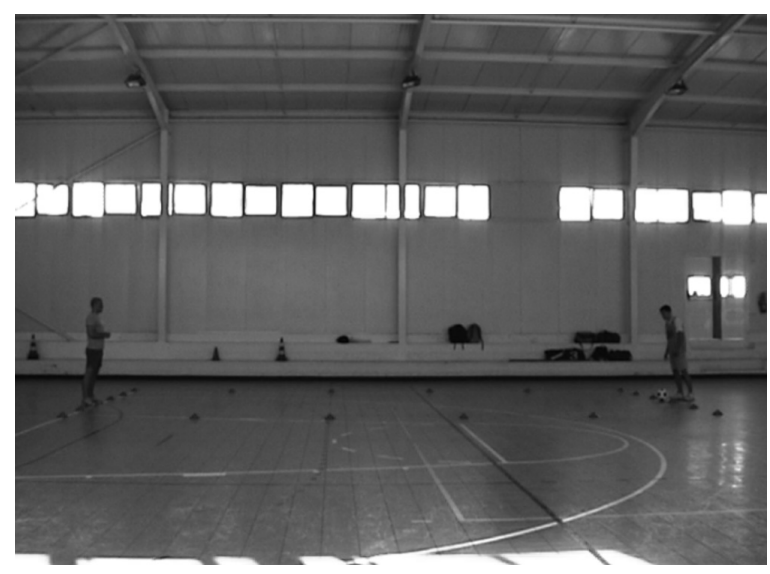

Figura 3. Imagem da câmara transversal. Do lado direito da figura está o jogador que ataca, do lado esquerdo da figura está o jogador que defende.

\section{Processamento das imagens}

As imagens foram armazenadas em suporte informático, via fire wire, utilizando o Pinnacle Studio versão 8.0 SE software e gravado em formato AVI. Para o tratamento das imagens, utilizou-se o software TACTO $7.0^{(8)}$, este software permite extrair os dados das coordenadas dos deslocamentos de cada jogador, digitalizando cada situação a vinte e cinco imagens por segundo. Os pontos digitalizados foram os seguintes: i) um ponto de trabalho junto ao chão, como se fosse uma projecção do centro de gravidade dos sujeitos, este ponto foi digitalizado: i) para o atacante; e ii) para o defesa. De forma a sincronizar a digitalização das imagens para ambos os jogadores, definiu-se como início de cada situação, o momento em que o atacante tocava com o pé na bola.

\section{Reconstrução do Espaço Bidimensional}

Para a reconstrução do espaço bidimensional foi utilizada a versão bidimensional(22) do método DLT (3). Esta versão designada 2D-DLT, permite reconstruir as coordenadas reais dos pontos localizados sobre um plano, através das coordenadas digitalizadas de imagens desses mesmos pontos e de um conjunto de pontos de referência, cuja localização real sobre o plano é conhecida. As câmaras de vídeo não obedecem a requisitos de orientação, dado que não é necessário o paralelismo entre o plano onde estão localizados os pontos e os planos de imagem das câmaras. Com o objectivo de garantir uma utilização amigável por parte do utilizador, foi desenvolvido um software que implementa os requisitos mínimos do método 2D-DLT. Estes requisitos, são 4 pontos de pontos de referência não colineares que formam um plano e uma câmara para registo de imagens. Para análise da dinâmica de aproximação entre os dois jogadores, optámos por tratar os dados de uma câmara colocada em posição transversal, sendo os 4 cantos do campo definidos como pontos de referência. O utilizador fornece os dados ao software através de um ficheiro de texto no qual são introduzidas as coordenadas reais em metros e as respectivas coordenadas digitalizadas dos 4 pontos de referência (cantos do campo). No mesmo ficheiro é introduzido um conjunto de coordenadas digitalizadas dos pontos (atacante, defesa ou bola) para os quais se 
pretende reconstruir as suas coordenadas reais. A execução do software, gera um ficheiro de texto que contém o resultado da reconstrução das coordenadas reais em metros, para o conjunto de pontos fornecidos. Para caracterizar a validade dos resultados da reconstrução do espaço bidimensional, foram utilizados os 36 pinos de sinalização dispostos no campo com espaçamentos pré-definidos. O erro de reconstrução é definido pela média da distância entre as posições reais medidas no campo e as respectivas posições reconstruídas dos 36 pinos. Para ponderar este valor em relação à área definida pelos 4 cantos do campo, foi definida uma área circular de raio dado pelo erro da reconstrução, dentro da qual se poderá encontrar o ponto reconstruído. Através do quociente entre estas áreas, obtemos o erro relativo da localização de um ponto reconstruído em relação à área do campo.

\section{Análise das variáveis dependentes}

Neste estudo foram calculadas as seguintes variáveis dependentes:

i) Distância do atacante e do defesa à linha de finalização. Esta variável mede a distância absoluta de cada jogador relativamente à linha de finalização (i.e. por onde o atacante tem de passar com a bola controlada conforme definido na tarefa, ver p. 370) ao longo do tempo. Esta variável foi calculada através da distância entre o ponto mais próximo da linha de finalização e cada jogador em linha recta. Foi calibrada em centímetros e colocada num gráfico posição-tempo bidimensional.

ii) Distância do atacante e do defesa às duas linhas laterais. Esta variável mede a distância absoluta de cada jogador relativamente às linhas laterais. Foi calibrada em metros e demonstrada em gráficos bidimensionais.

\section{RESULTADOS}

Neste capítulo começaremos por apresentar os resultados das trajectórias dos jogadores a partir da reconstrução do espaço bidimensional. De seguida, passamos à análise das transições de fase utilizando os gráficos bidimensionais posição-tempo, por forma a certificarmo-nos que identificamos as mesmas propriedades dos sistemas dinâmicos para o futebol, já encontradas para o basquetebol(17) e para o rugby(15).

\section{Validade da reconstrução do espaço bidimensional} O método 2D-DLT utilizado demonstrou validade na reconstrução do espaço bidimensional, com utilização de uma câmara de vídeo e 4 pontos de referência. O erro de reconstrução verificado foi de 0.170 metros, o que corresponde a um erro relativo de $0.2 \%$ da localização de um ponto reconstruído em relação à área do campo. Estes valores parecem aceitáveis na reconstrução válida das trajectórias de ambos os jogadores, permitindo estudar o comportamento de um sistema diádico como um fenómeno de interacção entre jogadores per si, mais do que como cada jogador funciona de forma isolada.

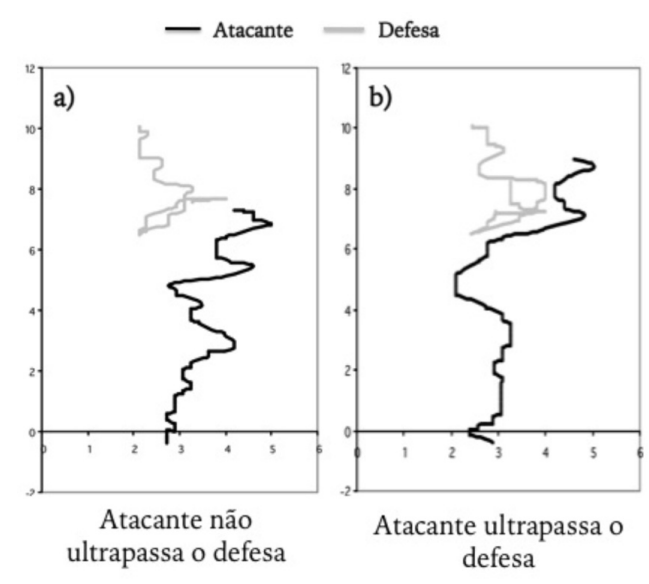

Figuras $4 a$ e $4 b$. Trajectória dos jogadores.

\section{Análise de propriedades dos sistemas dinâmicos no 1v1 no Futebol - transições de fase}

Para analisar as transições de fase, recorreu-se aos gráficos bidimensionais da distância de cada jogador ao objectivo em ordem ao tempo. Foram observados padrões de coordenação interpessoal já identificados nos estudos efectuados no rugby(15) e no basquetebol(17). Tal como nos estudos referenciados, os resultados revelam a existência de duas situações. Numa o sistema mantém o seu estado de ordem inicial (i.e. o atacante é o jogador mais afastado do objectivo), desde o início até ao final (Figura 5a). Nesta situação, o defesa mantém-se entre a bola e a linha final, contrabalançando de forma eficaz todas 


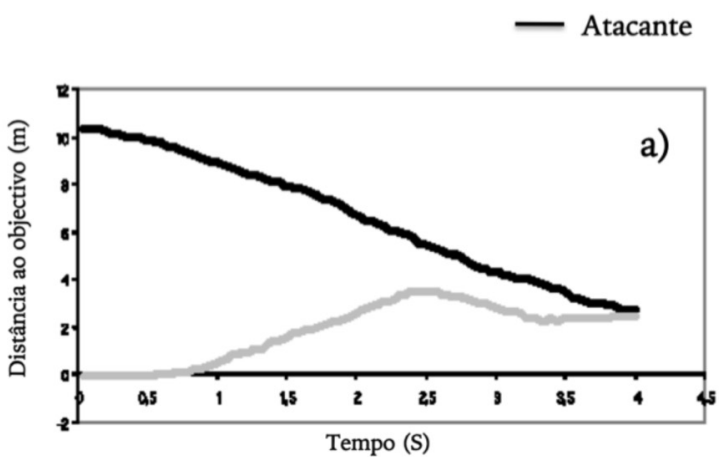

manutenção do estado de ordem, vantagem para o defesa

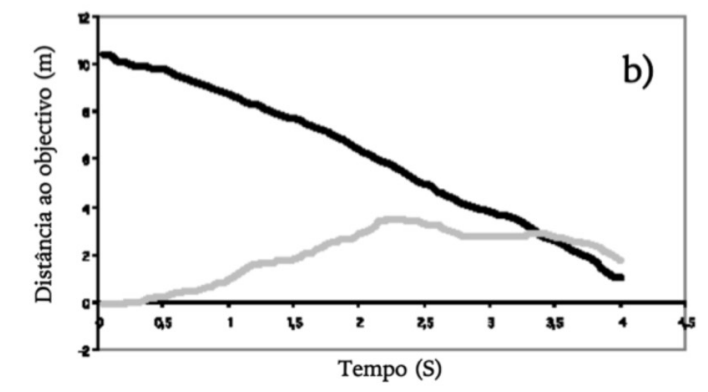

transição de fase, vantagem para $o$ atacante

Figuras $5 a$ e 5b. Distância de cada jogador ao objectivo.

as acções do atacante. Noutra situação (Figura 5b), observa-se, inicialmente, a manutenção do estado de ordem inicial, mas perto dos 3, 4 segundos, o atacante ultrapassa o defesa e fica em vantagem, tal como para os estudos de Ribeiro e colegas ${ }^{(17)}$ e Passos e colegas(15) para o basquetebol e para o rugby respectivamente, verifica-se também para o um-contra-um no Futebol uma transição de fase. Esta propriedade dos sistemas dinâmicos (i.e. transição de fase) é representada através da intercepção (i.e. cruzamento) das linhas, ficando o atacante mais próximo do objectivo, dando-se uma ruptura na estrutura organizacional que a díade atacante-defesa apresentava inicialmente.

\section{DISCUSSÃO}

Uma análise global dos dados, revela que este método de investigação permite recolher dados de forma directa para a reconstrução do espaço bidimensional, resultando numa análise de dados com séries temporais contínuas não-lineares, que representam a dinâmica interpessoal numa comum sub-fase do jogo de futebol.

De forma sumária, este estudo permitiu a identificação de transições de fase em mais um desporto de equipa com bola, com constrangimentos de tarefa diferentes do basquetebol e do rugby. Para alcançarmos este objectivo recorremos à análise de uma sub- fase do jogo de futebol, o um-contra-um. Os dados demonstram que com utilização de gráficos bidimensionais posição-tempo é possível identificar propriedades dos sistemas dinâmicos, tais como, as transições de fase, em tudo semelhantes às encontradas no basquetebol e no rugby. Os resultados alcançados demonstram que as DLT_2D são um método fiável para a reconstrução do espaço bidimensional, a partir do qual nos é permitido uma análise de trajectórias dos jogadores em cada instante no tempo.

\section{Análise das Transições de Fase}

Os resultados revelam que o comportamento de ambos os jogadores envolvidos na díade atacantedefesa, emerge a partir de um processo exploratório do envolvimento. Os dados indicam que a tomada de decisão em desportos de equipa, exemplificada aqui com situações de um-contra-um, pode ser caracterizada como um processo auto-organizado o qual depende de interacções específicas em curso entre um atacante e um defesa numa díade. De facto, os resultados podem ser interpretados como demonstrações de duas propriedades chave dos sistemas dinâmicos auto-organizados: i) a manutenção do estado de ordem inicial o qual se traduz numa vantagem para o defesa (Figure 5a); ii) uma transição de fase caracterizada pelo momento em que o atacante passa pelo defesa (Figure 5b). 
Podemos então sugerir que a tomada de decisão do atacante não pode ser exclusivamente determinada por intenções previamente definidas (e.g. vou passar o defesa pela direita), as decisões e acções têm de emergir da exploração de características específicas do contexto (i.e. dimensões do campo, distância interpessoal, velocidade relativa dos jogadores, etc.). A acção do defesa e as possibilidades de acção do atacante são constrangimentos situacionais que influenciam a decisão do atacante.

Numa perspectiva aplicada, os resultados sugerem que não existem modelos ideais de execução, nem para o atacante nem para o defesa. A aplicação dos pressupostos da teoria dos sistemas dinâmicos foca na necessidade de analisarmos a variabilidade na execução da técnica, e não centrarmos a nossa observação em algo que é assumido como um modelo ideal de execução, que muitas vezes não é ajustável aos constrangimentos individuais de cada jogador. Como tal, não é desejável determinar antecipadamente qual o gesto técnico a desempenhar. Do ponto de vista do processo ensino aprendizagem, sugerimos criar condições de prática, onde os jogadores activamente explorem o contexto na procura da melhor via para alcançar o objectivo. Nestes contextos de prática, a estabilidade das acções é conseguida pela limitação imposta pelos constrangimentos do praticante (p. ex. capacidades técnicas, tácticas, físicas e psicológicas) e da tarefa (p. ex. dimensões do campo, número de jogadores adversários), porém, a forma como através da decisão e acção exploram o contexto na procura do objectivo exige variabilidade na execução, numa contínua adaptação às exigências específicas do envolvimento. Em suma os dados sugerem que os treinadores devem assentar a sua prática na manipulação de constrangimentos de tarefa (p.ex. aumentar ou diminuir as dimensões do campo) para aumentar ou diminuir a dificuldade da tarefa, desta forma o desempenho dos jogadores para manter um comportamento direccionado para o objectivo, é constrangido pelas exigências específicas de cada situação particular.

No presente estudo, o facto de no um-contra-um o atacante não ter como objectivo finalizar numa baliza (objectivo principal do jogo de futebol) mas sim ultrapassar uma linha com a bola controlada, tendo como tal que ultrapassar o defesa, foi uma situação que pode representar as sub-fases de um-contra-um em qualquer parte do campo. O objectivo foi constranger a tarefa, de forma a que o atacante para conseguir alcançar o seu objectivo, ultrapassar a linha final com a bola controlada, tivesse que ultrapassar o defesa, dando possibilidade de estudarmos as dinâmicas de interacção e aproximação entre os dois jogadores em oposição. Ao utilizar-se uma baliza o atacante não precisaria de ultrapassar o defesa para alcançar o seu objectivo, podendo efectuar o remate mesmo com o defesa entre a bola e a baliza, ou o defesa podia optar por ficar entre postes com o intuito de procurar defender um remate do atacante. Contudo, esta deverá ser uma situação a estudar, comparando a emergência da tomada de decisão nesta situação com a do estudo aqui apresentado. Ao ter-se registado em $75 \%$ das situações que o estado de ordem inicial se manteve, podemos sugerir que existiu vantagem do defesa sobre o atacante. Uma possível justificação para esta ocorrência poderá ser a maior simplicidade das acções técnicas sem bola. Pelo contrário, as acções do atacante apresentam maior complexidade, na medida em que tem de controlar um objecto externo ao próprio corpo. Para confirmar esta suposição, sugere-se a realização de um estudo sobre a complexidade das acções do atacante e do defesa.

\section{Análise do instrumento de reconstrução do espaço bidimensional}

Actualmente os métodos naturalistas para o estudo da tomada de decisão(14) estão a ganhar popularidade, tal como referiu Bruce Abernethy no último congresso mundial de Psicologia do Desporto "Não se trata de trazer os atletas para dentro do laboratório mas sim levar o laboratório para o campo"(13). Neste enquadramento, a principal vantagem no método DLT é ausência da necessidade de se conhecerem os parâmetros intrínsecos ou extrínsecos da câmara, tais como distância focal, e o posicionamento da câmara em relação à origem. Para além disso, os resultados produzidos pelo método DLT são suficientemente precisos mesmo na presença de distorção óptica e/ou digital. Embora a utilização dos requisitos mínimos do método 2D-DLT diminua o grau de fiabilidade dos resultados, a principal vantagem na utilização deste método na perspectiva do utilizador, 
reside no conjunto necessário de pontos de referência suficientemente pequeno (quatro cantos do campo) e na utilização de uma única câmara. Igualmente vantajoso na fase de utilização do software desenvolvido, a entrada e saída de dados por ficheiros de texto permite que a manipulação de dados seja simples e sem restrições quanto à utilização de software alternativo para a digitalização e análise de dados.

Com base nas características deste instrumento, a sua utilização é proposta para outras situações desportivas, em que o investigador garanta o conhecimento do posicionamento real dos quatro pontos de referência e a respectiva filmagem do desempenho dos atletas.

\section{CONCLUSÕES}

O principal objectivo do estudo foi identificar propriedades dos sistemas dinâmicos tais como, as transições de fase num desporto de equipa com bola, com características tão específicas e com constrangimentos de tarefa diferentes dos do basquetebol e dos do rugby. Para alcançar este objectivo fomos analisar uma sub-fase do jogo de futebol, o um-contraum. Os dados recolhidos mostram, que utilizando gráficos da distância de cada jogador ao objectivo em ordem ao tempo é possível identificar transições de fase, tal como no basquetebol(17) e no rugby(15). De onde podemos concluir que o um-contra-um no futebol se comporta como um sistema dinâmico. Com base nos resultados obtidos, podemos concluir que a decisão do atacante de quando e onde ultrapassar o defesa é um processo auto-organizado, que depende da sua interacção com o defesa.

Considerando o um-contra-um como um sistema dinâmico auto-organizado, o comportamento do defesa e do atacante não é conduzido exclusivamente por informação exterior (p.ex. instrução do treinador) ou por informação posteriormente armazenada na memória, mas sim pela informação que é gerada na interacção entre um jogador e o contexto específico em que determinada tarefa é desempenhada ${ }^{(4)}$. As possibilidades de acção (i.e. affordances), ou seja, aquilo que o contexto permite realizar, são influenciadas pelos objectivos dos jogadores, pelas suas intenções e pelas suas características morfológicas e capacidades técnico-tácticas, assim como pelos limi- tes do campo, e pelas acções do seu adversário directo. A interacção mútua e recíproca que se estabelece entre os vários constrangimentos da acção no $1 \mathrm{v} 1$ no futebol conduz a um processo auto-organizado (i.e. sem qualquer ordem exterior) que pode ser caracterizado através de duas situações: i) o sistema mantém o estado de ordem do início ao fim, com vantagem para o defesa (Figura 5a); e ii) ocorre uma transição de fase, quando o atacante ultrapassa o defesa ganhando vantagem (Figura 5b).

Como instrumento de reconstrução bidimensional foi utilizado o método 2D-DLT com os requisitos mínimos de quatro pontos de referência e uma câmara de vídeo. Este método foi implementado através do desenvolvimento de um software específico focado na utilização amigável na perspectiva do utilizador. Concluímos que a aplicação do instrumento demonstrou ser consistente para uma análise fenomenológica de situações de um-contra-um no futebol, o que sugere que a sua aplicação seja extensível a diferentes cenários desportivos, na análise da tomada de decisão e coordenação interpessoal em tarefas desportivas.

\section{CORRESPONDÊNCIA}

\section{Pedro José Madaleno Passos}

Universidade Lusófona

de Humanidades e Tecnologias

Departamento de Educação Física,

Desporto e Lazer

Campo Grande, 376, Lisboa

Fax: 217515544

E-mail:p.passos@clix.pt 


\section{REFERÊNCIAS BIBLIOGRÁFICAS}

1. Abernethy, B., Kippers, V., MacKinnon, L.T., Neal, R.J., Hanrahan, S. (1997). The Biophysical Foundations of Human Movement. Human Kinetics.

2. Abernethy, B.(2005) Comunicação no Congresso Mundial de Psicologia do Desporto, Austrália, Sydney.

3. Abdel-Aziz, Y. I., \& Karara, H. M. (1971). Direct linear transformation from comparator coordinates into object space coordinates in close-range photogrammetry. Comunication presented at the Symposium on Close-Range Photogrammetry, Falls Church, VA.

4. Araújo, D. (2005). O Contexto da Decisão - A Acção Táctica no Desporto. Lisboa: Ed. Visão e Contextos.

5. Araújo, D. (2006). Tomada de Decisão no Desporto. Lisboa: Ed. FMH.

6. Bernstein, N. (1967). The coordination and regulation of movements. Oxford: Pergamon Press.

7. Castelo, J. (2003). Futebol, Actividades Físicas e Desportivas. Lisboa: Ed. FMH.

8. Fernandes, O. \& Caixinha, P. (2003). A new method in timemotion analysis in soccer training and competition. Comunication presented at the $5^{\text {th }}$ world congress of science \& Football (pp.270-271), Lisbon.

9. Gibbs, R. (2006). Embodiment and Cognitive Science. Cambridge University Press.

10. Gibson, J.J. (1979). An Ecological Approach to Visual Perception. Boston, MA: Houghton-Mifflin.

11. Júlio, L. e Araújo, D. (2005). A abordagem dinâmica da acção táctica no jogo de Futebol. In D. Araújo (Ed.). O Contexto da Decisão: A Aç̧ão Táctica no Desporto. Cap. 10, pp. 157-178. Visão e Contextos.

12. Klein, G. (2001). The fiction of optimization. In G. Gigerenzer, \& R. Stelten (Ed.), Bounded Rationality. The adaptive toolbox. Massachusetts: MIT, 103-121

13. McGarry, T., Anderson, D., Wallace, S., Hughes, M. e Franks, I. (2002). Sport competition as dynamical selforganizing system. J Sport Sci 20(10): 771-781.
14. Newell, K. M. (1986). Constraints on the Development of Coordination. In M. Wade \& H.T.A.Whiting (Eds.), Motor Development in Children: Aspects of Coordination and Control.. Dordrecht, Netherlands: Martinus Nijhoff, 341-360

15. Passos, Araújo, Davids, Gouveia \& Serpa (2006). Interpersonal Dynamics in Sport: The Role of Artificial Neural Networks and Three-dimensional Analysis. Behav Res Methods 38(4): 683-691.

16. Passos, P., Araújo, D., Davids, K. \& Shuttleworth, R. (2008). Manipulating Constraints to Train Decision Making in Rugby Union. Int J Sports Sci_Coaching March, 3(1): 125-140(16).

17. Ribeiro, J., Araújo, D. e Serpa, S. (2003). A dinâmica da tomada de decisão na relação um-contra-um no basquetebol: relação entre cognições e acções. In P. Castro, R. Novo, M. Garrido, R. Pires, e C. Moreno (Ed.), V Simpósio Nacional de Investigação em Psicologia (pp. 106-107). Lisboa: Associação Portuguesa de Psicologia.

18. Schöner, G. (1990). A Dynamic Theory of Coordination of Discrete Movement. Biol Cyber 63: 257-270.

19. Seeley, T.D. (2001). Decision Making in superorganisms: how collective wisdom arises from the poorly informed masses. In G. Gigerenzer, R. Stelten (Ed.). Bounded Rationality: The adaptive toolbox. Massachusetts: MIT press, 249-261

20. Starkes, J., Helsen, W. \& Jack, R. (2001). Expert Performance in Sport and Dance. In R. Singer, H. Hausenblas, C. Janelle (Eds.) Handbook of Sport Psychology. Chichester: John Wiley, 174-201

21. Turvey, M. (1990), Coordination. Am Psychol 45: 938-953.

22. Walton, J. S. (1981). Close-range cine-photogrammetry: a generalized technique for quantifying gross human motion. Unpublished Ph.D. Dissertation, Pennsylvania State University, University Park.

23. Williams, A.M., Davids, K. \& Williams, J.G. (1999). Visual Perception and Action in Sport. London: Routledge. 